\title{
Nanostructuring the Er-Yb distribution to improve the photoluminescence response of thin films
}

\author{
A. Suarez-Garcia, R. Serna, ${ }^{a)}$ M. Jiménez de Castro, and C. N. Afonso \\ Instituto de Óptica, CSIC, Serrano 121, 28006 Madrid, Spain \\ I. Vickridge \\ GPS, Universités Paris VI et VII, UMR7588, Tour 23 2, Place Jussieu, 75251-Paris Cedex 5, France
}

(Received 14 August 2003; accepted 7 January 2004)

\begin{abstract}
Thin films of amorphous aluminum oxide $\left(a-\mathrm{Al}_{2} \mathrm{O}_{3}\right)$ codoped with $\mathrm{Er}^{3+}$ and $\mathrm{Yb}^{3+}$ ions have been in-depth nanostructured by distributing the rate earth (RE) ions in layers separated in the $0-3 \mathrm{~nm}$ range. The $\mathrm{Yb}$ to Er concentration ratio is varied from 0 to 3.6. The photoluminescence (PL) response at $1.53 \mu \mathrm{m}$ exhibits an increase of up to two orders of magnitude with respect to that of films doped only with Er. The PL intensity is improved when $\mathrm{Yb}^{3+}$ and $\mathrm{Er}^{3+}$ ions are in separate layers and the results show that efficient $\mathrm{Yb}^{3+}$ to $\mathrm{Er}^{3+}$ energy transfer can be achieved for separations up to $3 \mathrm{~nm}$. Furthermore, it is shown that designing an adequate RE distribution, for the same total RE content and $\mathrm{Yb}$ to Er concentration ratio, can enhance the PL intensity by a further factor of two. It is shown that the $\mathrm{Er}^{3+} \mathrm{PL}$ response is improved because of a reduction of the RE clustering and an improvement of the energy transfer from $\mathrm{Yb}^{3+}$ to $\mathrm{Er}^{3+}$ ions. (C) 2004 American Institute of Physics. [DOI: 10.1063/1.1664034]
\end{abstract}

In scaling down the system dimensions to substitute the Er doped fiber amplifier by an integrated device, thin films with an Er content two orders of magnitude higher with respect to that of fibers are required in order to achieve comparable levels of optical gain. ${ }^{1}$ Processes related to cooperative interaction between neighboring $\mathrm{Er}$ ions such as upconversion and inter-ion energy migration become a key issue. Another important aspect is the enhancement of the $\mathrm{Er}^{3+}$ absorption in the range of $980 \mathrm{~nm}$ where integrated semiconductor diode lasers operate. $\mathrm{Yb}^{3+}$ has been broadly used as a sensitizer for the $\mathrm{Er}^{3+}$ absorption since, upon deexcitation of the $\mathrm{Yb}^{3+}$ ions, the energy is resonantly transferred by nonradiative dipolar interaction to the $\mathrm{Er}^{3+}$ ions. ${ }^{2,3}$ Using $\mathrm{Yb}^{3+}$ codoping a successful integrated amplifier in phosphate glass has been reported. ${ }^{4}$ The $\mathrm{Yb}$ to $\mathrm{Er}$ (Yb:Er) concentration ratio usually determines the optimum Er photoluminescence (PL) response. ${ }^{5-8}$ However, it has been evidenced that the mean separation between $\mathrm{Er}^{3+}$ and $\mathrm{Yb}^{3+}$ ions is a fundamental parameter in the energy transfer process and therefore the rare earth (RE) ion spatial distribution in the matrix is expected to play an important role in the PL response. ${ }^{2}$ Indeed, in our earlier studies on Er-doped amorphous aluminum oxide $\left(a-\mathrm{Al}_{2} \mathrm{O}_{3}\right)$ films, we have shown that nanostructuring the Er distribution was essential for an improved PL performance. ${ }^{9,10}$ The aim of this work is to show that the photoluminescence response of $\mathrm{Er}-\mathrm{Yb}$ codoped $a-\mathrm{Al}_{2} \mathrm{O}_{3}$ films can be optimized by nanostructuring the $\mathrm{RE}$ distribution, namely by controlling the $\mathrm{Yb}^{3+}$ to $\mathrm{Er}^{3+}$ ions separation independently of the $\mathrm{Yb}: \mathrm{Er}$ concentration ratio. The study has been performed for two different $\mathrm{Yb}$ :Er concentration ratios.

The samples have been grown by pulsed laser deposition (PLD) on Si substrates held at room temperature in vacuum

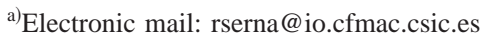

( $10^{-6}$ Torr). An ArF excimer laser $(\lambda=193 \mathrm{~nm}, \tau=12 \mathrm{~ns}$ full width at half maximum) with an energy density of $\sim 2.5$ $\mathrm{J} / \mathrm{cm}^{2}$ was alternatively focused on $\mathrm{Al}_{2} \mathrm{O}_{3}, \mathrm{Er}$, and $\mathrm{Yb}$ targets. The $a-\mathrm{Al}_{2} \mathrm{O}_{3}$ deposition rate was $9 \times 10^{-3} \mathrm{~nm} / \mathrm{pulse}$, which means that a fine control on the nanometer scale of the $a-\mathrm{Al}_{2} \mathrm{O}_{3}$ thickness can be achieved. Each time the $\mathrm{RE}$ ions are deposited on the surface of previously grown $a-\mathrm{Al}_{2} \mathrm{O}_{3}$, a RE-doped layer is created. In this way, films with RE-doped layers at fixed in-depth positions have been formed. ${ }^{11} \mathrm{~A}$ reference film has been synthesized doped only with $\mathrm{Er}^{3+}$. The film consists of 50 alternate $a-\mathrm{Al}_{2} \mathrm{O}_{3} /$ RE-doped layers with an in-depth separation between consecutive Er-doped layers of $6 \mathrm{~nm}$. This structure has been chosen since we have earlier shown that the PL response was optimized for films with this Er-Er in-depth separation. ${ }^{10}$ The configuration of the Erdoped layers for the case of the codoped films is the same as in the reference film, with the additional Yb-doped layers located at different in depth separations from the Er-doped ones. Figure 1 shows a scheme of the resulting in-depth distribution of the RE. The $\mathrm{Yb}$ to Er doped layer in-depth separation $(S)$ has been selected to be $0 \mathrm{~nm}\left(\mathrm{Er}^{3+}\right.$ and $\mathrm{Yb}^{3+}$ ions together in the same layer), 1 or $3 \mathrm{~nm}$. The $\mathrm{Yb}: \mathrm{Er}$ concentration ratio has been varied through the number of laser pulses on the $\mathrm{Yb}$ target per doped layer, that was chosen to be either 1 or 2. Finally a reference film doped only with $\mathrm{Yb}$ and with the same structure as the Er reference film has been grown. Table I summarizes the synthesis parameters of each film.

The RE content and the total thickness have been determined by Rutherford backscattering spectroscopy (RBS) using a $2 \mathrm{MeV} \mathrm{He}{ }^{+}$beam and a scattering angle of $15^{\circ}$. The total thickness has been determined to be $(310 \pm 20) \mathrm{nm}$, which is in excellent agreement with the value estimated from the deposition rate of the $a-\mathrm{Al}_{2} \mathrm{O}_{3}$ and consequently confirms that the separation between Er and $\mathrm{Yb}$ layers is 


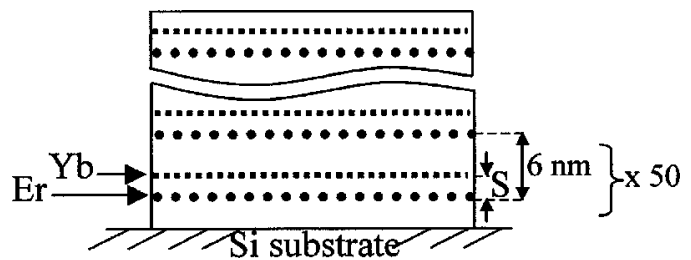

FIG. 1. Schematics of the in-depth distribution of the Er (dots) and $\mathrm{Yb}$ (dash) doped layers in the films. The separation between two consecutive Er doped layers is fixed to $6 \mathrm{~nm}$ and $\mathrm{S}$ indicates the variable $\mathrm{Er}$ to $\mathrm{Yb}$ dopedlayers separation. The film structure consists of 50 repetitions of the deposition sequence $\mathrm{Er} / a-\mathrm{Al}_{2} \mathrm{O}_{3}(S \mathrm{~nm}) / \mathrm{Yb} / a-\mathrm{Al}_{2} \mathrm{O}_{3}[(6-S) \mathrm{nm}]$.

equal to the assumed values $(0,1$, and $3 \mathrm{~nm})$ within an error of $6 \%$. The RBS spectra show a single peak related to the total RE content in the films since the close atomic number of $\mathrm{Er}$ and $\mathrm{Yb}$ (Er: 68, $\mathrm{Yb}$ : 70) prevents discrimination between them. From the measurement of the reference films, doped only with Er and only with $\mathrm{Yb}$, respectively, it has been calculated that $1.1 \times 10^{14} \mathrm{at} / \mathrm{cm}^{2}$ of $\mathrm{Er}$ and 2.0 $\times 10^{14} \mathrm{at} / \mathrm{cm}^{2}$ of $\mathrm{Yb}$ have been deposited per respective laser pulse. These values vary within $10 \%$ from sample to sample due to fluctuations in the deposition rate of the RE. The $\mathrm{Yb}$ :Er concentration ratio in the codoped films synthesized with one $\mathrm{Yb}$ and one Er laser pulse per layer is 1.8 and for films with two $\mathrm{Yb}$ pulses per layer it is 3.6. Note that the Er content in all the films is the same, within the experimental error.

The films were annealed in air after deposition up to $850{ }^{\circ} \mathrm{C}$, following the step annealing procedure described elsewhere. ${ }^{9}$ The PL measurements were subsequently performed at room temperature using a liquid-nitrogen cooled Ge detector and a cw Ti:sapphire laser as the excitation source, with an incidence angle of $25^{\circ}$.

$\mathrm{Er}^{3+}$ doped $a-\mathrm{Al}_{2} \mathrm{O}_{3}$ films exhibit the characteristic emission band peaking at $1.53 \mu \mathrm{m}$ which corresponds to the ${ }^{4} I_{13 / 2} \rightarrow{ }^{4} I_{15 / 2}$ transition of $\mathrm{Er}^{3+}$ ions. ${ }^{12,13}$ PL excitation spectrum has been normalized for an excitation power of 200 $\mathrm{mW}$. Figure 2 shows the PL excitation spectrum for both the reference film doped only with $\mathrm{Er}^{3+}$ and one of the codoped films. For the former, PL is detected only under excitation in a narrow range $(F W H M \sim 10 \mathrm{~nm})$ centered on $975 \pm 3 \mathrm{~nm}$. This absorption band corresponds to the ${ }^{4} I_{15 / 2} \rightarrow{ }^{4} I_{11 / 2}$ transition of $\mathrm{Er}^{3+}$ ions. However, PL is detected in all the measured range of wavelengths for the codoped film. Thus, the

TABLE I. Summary of the samples studied in this work and their deposition conditions: the number of pulses on the $\mathrm{Er}$ and $\mathrm{Yb}$ targets, the Er-Yb indepth separation $(S)$ and the total rare earth content $([\mathrm{RE}])$ in the film, determined by RBS.

\begin{tabular}{lcccc}
\hline \hline Sample & $\begin{array}{c}\text { No. pulses } \\
\text { on Er }\end{array}$ & $\begin{array}{c}\text { No. pulses } \\
\text { on Yb }\end{array}$ & $\begin{array}{c}S \\
(\mathrm{~nm})\end{array}$ & $\begin{array}{c}(\mathrm{RE}) \\
\left(\times 10^{16} \mathrm{at} \mathrm{cm}^{-2}\right)\end{array}$ \\
\hline Er & 1 & - & - & 0.6 \\
Yb & - & 1 & - & 1.0 \\
ErYb 1-0 & 1 & 1 & 0 & 1.7 \\
ErYb 1-1 & 1 & 1 & 1 & 1.7 \\
ErYb 1-3 & 1 & 1 & 3 & 1.6 \\
ErYb 2-0 & 1 & 2 & 0 & 2.5 \\
ErYb 2-3 & 1 & 2 & 3 & 3.0 \\
ErYb 2-1 & 1 & 2 & 1 & 2.8 \\
\hline \hline
\end{tabular}

${ }^{\mathrm{a}}$ Two pulses on the $\mathrm{Yb}$ target are distributed in two separate layers, one on

luminescence can be responsible for the relatively low PL
Downloaded 19 Feb 2010 to 161.111 .180 .191 . Redistribution subject to AIP license or copyright; see http://apl.aip.org/apl/copyright.jsp

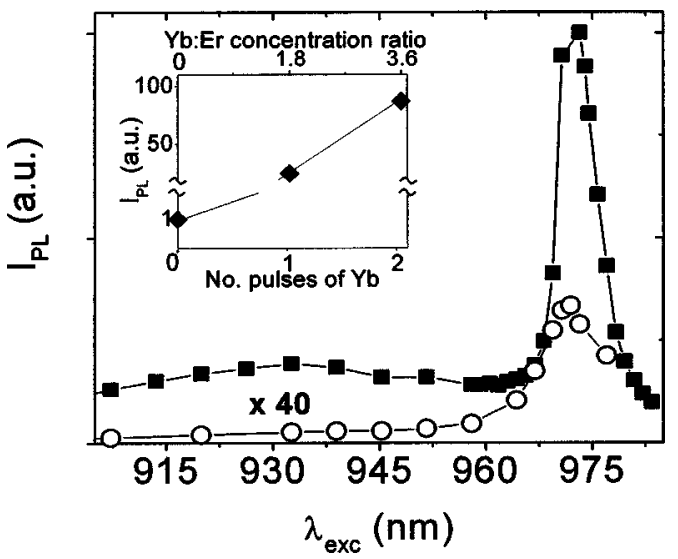

FIG. 2. PL excitation spectra measured at $1.53 \mu \mathrm{m}$ for an Er doped (O) and an $\mathrm{Er}-\mathrm{Yb}$ codoped (ם) film. The values for the film doped only with $\mathrm{Er}$ have been multiplied by a factor of 40. The inset shows the PL intensity at $1.53 \mu \mathrm{m}$ pumped at $975 \mathrm{~nm}$ as a function of the number of pulses on the $\mathrm{Yb}$ target per layer (lower axis) and the $\mathrm{Yb}$ :Er concentration ratio (upper axis) for films with $S=0 \mathrm{~nm}$. Note the change of scale in the vertical axis for the film doped only with $\mathrm{Er}(\mathrm{Yb}: \mathrm{Er}$ concentration ratio=0).

existence of an efficient energy transfer process from $\mathrm{Yb}^{3+}$ to $\mathrm{Er}^{3+}$ ions is evidenced since the excitation range corresponds to the ${ }^{2} F_{7 / 2} \rightarrow{ }^{2} F_{5 / 2}$ transition band of $\mathrm{Yb}^{3+}$. The highest emission intensity for both films corresponds to $975 \pm 3 \mathrm{~nm}$, being higher for the codoped film due to the larger absorption cross section of the $\mathrm{Yb}^{3+}$ ions. ${ }^{3}$ In the folthe PL response of the films.

The inset of Fig. 2 shows the PL intensity as a function of the number of pulses on the $\mathrm{Yb}$ target (bottom axis) or the $\mathrm{Yb}:$ Er concentration ratio in the films (top axis). In both axes, the value equal to zero corresponds to the film doped only with Er. The plotted values are representative of the behavior exhibited by all the codoped films. The PL intensity is shown to increase with the $\mathrm{Yb}: \mathrm{Er}$ concentration ratio with no tendency to saturate. For the $\mathrm{Yb}$ :Er concentration ratio of 3.6 there is an increase of two orders of magnitude with respect to the film doped only with Er. Note that the local $\mathrm{Yb}$ in-plane concentration for this film is very large, equal to 4 $\times 10^{14} \mathrm{at} / \mathrm{cm}^{2}$. This concentration is equivalent to an $\mathrm{Yb}-\mathrm{Yb}$ mean in plane separation of only $0.5 \mathrm{~nm}$, assuming a homogeneous in plane distribution of the ions, so quenching processes due to clustering among $\mathrm{Yb}^{3+}$ ions can occur. ${ }^{14}$ However, the fact that the PL intensity is increasing as a function of the $\mathrm{Yb}$ content, within the studied range, suggests that the increase of the number of optically active ions available to absorb the excitation energy dominates over the increase of the number of nonactive ions forming clusters.

Figure 3 shows the PL intensity as a function of the separation from the Er to the $\mathrm{Yb}$ layers for the two studied $\mathrm{Yb}:$ Er concentration ratios. The films with $\mathrm{Er}^{3+}$ and $\mathrm{Yb}^{3+}$ ions together in the same layer, i.e., $S=0 \mathrm{~nm}$, always exhibit the lowest PL intensity. Note that, in this case, despite the $\mathrm{Yb}^{3+}$ to $\mathrm{Er}^{3+}$ ion separation in the direction perpendicular to the plane is $0 \mathrm{~nm}$, the estimated in-plane average separation is $0.5 \mathrm{~nm}$, assuming an in-plane homogeneous distribution of the RE ions. This value confirms that the local RE concentration is very high and, consequently, the quenching of the luminescence can be responsible for the relatively low PL lowing, this will be the excitation wavelength to characterize 


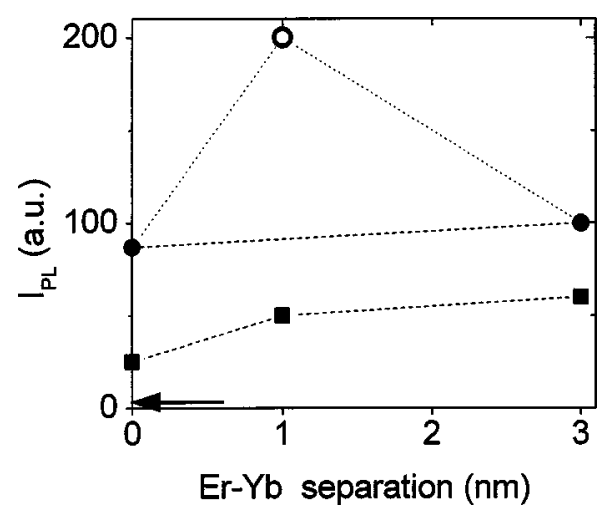

FIG. 3. PL intensity at $1.53 \mu \mathrm{m}$ pumped at $975 \mathrm{~nm}$ as a function of the Er to $\mathrm{Yb}$ layer separation for films with a $\mathrm{Yb}$ :Er concentration ratio equal to 1.8 $(\square)$ and $3.6(\bullet),(\bigcirc)$. The arrow indicates the PL intensity obtained for the film doped only with Er. For the films (-) the two pulses on $\mathrm{Yb}$ are in the same doped-layer whereas for the film $(\bigcirc)$ each pulse on $\mathrm{Yb}$ corresponds to a separate layer, one above and the other below the Er layer.

intensity observed. Figure 3 shows that, for the lowest $\mathrm{Yb}: \mathrm{Er}$ concentration ratio (1.8), the PL intensity increases a factor of 2 when $S$ increases from 0 to $1 \mathrm{~nm}$. This result is probably due to a decrease of the RE mutual clustering as a consequence of locating the $\mathrm{Er}^{3+}$ and $\mathrm{Yb}^{3+}$ ions in different layers. Nevertheless, it should also be noted that the probability of nonradiative energy transfer from $\mathrm{Yb}^{3+}$ to $\mathrm{Er}^{3+}$ ions decreases as a sixth power of the $\mathrm{Yb}^{3+}$ to $\mathrm{Er}^{3+}$ separation due to its dipolar nature. ${ }^{2,6}$ Therefore, the observed increment in the PL intensity for $S=1 \mathrm{~nm}$ means that the reduction of clustering dominates over the decrease of the probability of energy transfer from $\mathrm{Yb}^{3+}$ to $\mathrm{Er}^{3+}$. In the literature, a critical separation has been defined as the $\mathrm{Yb}^{3+}$ to $\mathrm{Er}^{3+}$ separation at which the probability of the nonradiative energy transfer to an $\mathrm{Er}^{3+}$ ion is equal to the probability of radiative emission from the $\mathrm{Yb}^{3+}$. This means that for separations larger than the critical separation, the probability of energy transfer is greatly reduced. Critical separation values of the order of $1.5 \mathrm{~nm}$ have been reported for $\mathrm{Yb}^{3+}$ and $\mathrm{Er}^{3+}$ ions embedded in matrices of different nature. ${ }^{6,15,16}$ Nevertheless, Fig. 3 shows that the PL intensity for films with $S=3 \mathrm{~nm}$ is much higher than that for the reference film doped only with $\mathrm{Er}$, thus an $\mathrm{Yb}^{3+}$ to $\mathrm{Er}^{3+}$ energy transfer might be taking place even for $S=3 \mathrm{~nm}$. Furthermore, for the case of $\mathrm{Yb}: \mathrm{Er}$ concentration equal to 1.8 , the PL intensity is even higher than for $S=1 \mathrm{~nm}$. This improvement cannot be explained in terms of reduction of the clustering since the local concentration for the films with $S=3 \mathrm{~nm}$ might be similar to that for $S=1 \mathrm{~nm}$. Note that both distributions have the $\mathrm{Er}^{3+}$ and $\mathrm{Yb}^{3+}$ ions separated in different layers and with the same RE concentration per layer. Since the probability of nonradiative energy transfer is very low at such large separation $(3 \mathrm{~nm})$, it is suggested that the probability of energy transfer through photon emission, i.e., radiative energy transfer, might be playing a role.

Finally, a new film has been grown considering the previous results. It has been designed to have the highest total Yb content and $S=1 \mathrm{~nm}$, a separation short enough to allow the $\mathrm{Yb}$ to Er nonradiative energy transfer to be efficient while enough to avoid clustering of the rare earth ions. The new film is named ErYb2-1 in Table I and its Yb:Er concen- tration ratio is 3.6. In this new sample, the $\mathrm{Yb}$ was distributed in two layers, each grown by one pulse on $\mathrm{Yb}$, symmetrically distributed above and below the Er layer. The PL intensity measured in this film has also been plotted in Fig. 3 and is found to be the highest of all the analyzed films. Compared to the other films with an Yb:Er concentration ratio of 3.6, the PL intensity increases by a factor of 2.3. This increase can be a result of a reduction of the $\mathrm{Yb}$ clustering derived from the splitting of the two pulses on $\mathrm{Yb}$ in two separated layers, which means that the number of active $\mathrm{Yb}^{3+}$ ions has been effectively increased. ${ }^{14}$ The symmetry of the $\mathrm{Yb}$ distribution around $\mathrm{Er}$ ions, in addition to the appropriate inter-ion separation, could also contribute to the PL enhancement. This result is evidence that the Er PL can be improved by means of an appropriate design of the $\mathrm{Er}$ and $\mathrm{Yb}$ distribution on the nanometer scale.

In conclusion, $\mathrm{Er}-\mathrm{Yb}$ codoped films with a controlled distribution of the $\mathrm{Yb}^{3+}$ and $\mathrm{Er}^{3+}$ ions in layers with an in-depth separation in the $0-3 \mathrm{~nm}$ range have been successfully produced by PLD. The PL response of the codoped films is found to improve when the $\mathrm{Er}^{3+}$ and $\mathrm{Yb}^{3+}$ ions are in separate layers, independent of the $\mathrm{Yb}: \mathrm{Er}$ concentration ratio. In addition, an efficient energy transfer from $\mathrm{Yb}^{3+}$ to $\mathrm{Er}^{3+}$ has been found for ion separations up to $3 \mathrm{~nm}$, suggesting that both radiative and nonradiative $\mathrm{Yb}^{3+}$ to $\mathrm{Er}^{3+}$ energy transfer processes might be playing a role. Further analysis of the dependence of the PL response on the $\mathrm{Er}-\mathrm{Yb}$ distribution on the nanometer scale is needed since the present results open up new perspectives for optimizing the performance of waveguide gain devices.

This work was supported by CICYT (Spain) under TIC2002-03235 Project. The authors acknowledge J. Jiménez (Universidad de Valladolid, Spain) for supplying the Ti:sapphire laser.

${ }^{1}$ M. P. Hehlen, N. J. Cockroft, T. R. Gosnell, and A. J. Bruce, Phys. Rev. B 56, 9302 (1997).

${ }^{2}$ E. Desurvire, in Erbium Doped Fiber Amplifiers: Principles and Applications (Wiley, New York, 1994), Chap. 4.

${ }^{3}$ C. Strohhofer and A. Polman, J. Appl. Phys. 90, 4314 (2001).

${ }^{4}$ J.-M. P. Delavaux, S. Granlund, O. Mizuhara, L.-D. Tzeng, D. Barbier, M. Rattay, F. Saint André, and A. Kevorkian, IEEE Photonics Technol. Lett. 9, 247 (1997).

${ }^{5}$ A. Kozanecki, H. Przybylinska, W. Jantsch, and L. Palmetshofer, Appl. Phys. Lett. 75, 2041 (1999).

${ }^{6}$ L. D. da Vila, L. Gomes, L. V. G. Tarelho, S. J. L. Ribeiro, and Y. Messadeq, J. Appl. Phys. 93, 3873 (2003).

${ }^{7}$ M. Federighi and F. di Pasquale, IEEE Photonics Technol. Lett. 7, 303 (1995).

${ }^{8}$ Ch. Lester, A. Bjarklev, T. Rasmussen, and P. G. Dinesen, J. Lightwave Technol. 13, 740 (1995)

${ }^{9}$ R. Serna, M. Jiménez de Castro, J. A. Chaos, C. N. Afonso, and I. Vickridge, Appl. Phys. Lett. 75, 4073 (1999).

${ }^{10}$ R. Serna, M. Jiménez de Castro, J. A. Chaos, A. Suarez-Garcia, C. N. Afonso, M. Fernández, and I. Vickridge, J. Appl. Phys. 90, 5120 (2001).

${ }^{11}$ R. Serna, C. N. Afonso, C. Ricolleau, Y. Wang, Y. Zheng, M. Gandais, and I. Vickridge, Appl. Phys. A: Mater. Sci. Process. 71, 583 (2000).

${ }^{12}$ N. Van den Hoven, E. Snoeks, A. Polman, J. W. M. Van Uffelen, Y. S. Oei, and M. K. Smit, Appl. Phys. Lett. 62, 3065 (1993).

${ }^{13}$ R. Serna and C. N. Afonso, Appl. Phys. Lett. 69, 1541 (1996).

${ }^{14}$ P. Goldner, B. Schaudel, and M. Prassas, Phys. Rev. B 65, 054103 (2002).

${ }^{15}$ J. F. Philipps, T. Topfer, H. Ebendorff-Heidepriem, D. Ehrt, and R. Sauerbrey, Appl. Phys. B: Lasers Opt. 72, 399 (2001).

${ }^{16}$ O. Barbosa-García, L. A. Díaz-Torres, M. A. Menesses-Nava, J. F. Mosiño, and J. T. Vega-Durán, J. Electrochem. Soc. 149, J31 (2002). 